\title{
Teaching and Learning Modeling and Specification based on Mobile Devices and Cloud
}

\author{
Fernando Moreira \\ UPT, Portucalense Institute for Legal Research, DEGI, \\ Porto, Portugal \\ IEETA, UA, Aveiro, Portugal \\ fmoreira@upt.pt
}

\author{
Maria João Ferreira \\ UPT, DEGI, Porto, Portugal \\ ISTTOS, Algoritmi, UM, Braga, Portugal \\ mjoao@upt.pt
}

\begin{abstract}
In this paper, and in the context of a course of $1 \mathrm{st}$ cycle in Informatics, and following the guidelines of the Information Systems courses provided by ACM/AIS, we propose the use of Google tools and Lucidchart modeling tool, aligned with Bloom's taxonomy in our model BML Context Oriented (BML-CO) in a Requirements Engineering course based on Unified Modelling Language (UML) to modeling and specify requirements to a software system. Teaching Requirements Engineering and, in particular modeling and specification requirements, at the higher education institutions is an "arduous" task according to the literature that the proposed approach wants contribute for filling this gap.
\end{abstract}

Keywords - Requirements Engineering; Modeling, UML Teaching/Learning Process, m_Learning, Mobile Device, Cloud, Collaborative work

\section{INTRODUCTION}

Mobile devices have been gradually introduced in educational contexts in recent decades due to factors such as the new social needs in educational technologies, the development of market economy, improvement of forms and methods of learning [1]. Mobile technology has led most people to carry their own individual devices (laptops, tablets, smartphones, etc.) that already have a high computing power, storage, etc. This large amount of computing power and portability, combined with wireless tools and context sensitivity, makes these devices a great potential learning tool, both in the traditional classrooms, or in informal learning outdoors, taking the development of mobile learning (mlearning).

Educationally advanced countries have developed strong policies and strategies to address the educational needs of the XXI century. These countries are the pioneers in how to take advantage of mobile devices in the teaching-learning process (TLP). Some European countries have developed some mlearning projects, for example, in the UK, the MoLeNET ${ }^{1}$, has a sterling $£ 12$ million budget and 40,000 students. In Australia the feasibility and $\mathrm{m}$-learning sustainability is a topic of intense debate, because $65 \%$ of people have their own smartphone, $37 \%$ its own tablet, and about $1 / 3$ of the population have both devices [2].
Moreover, in terms of promoting innovation in education through various technologies (Web 2.0, cloud, etc.) have been adapted for teaching and learning [3], not only in supporting the traditional teaching, but also through the collection and sharing of information, also can promote innovative methods of teaching through cooperative learning, exploratory learning outside the classroom, and games-based learning [4].

When the learning environment is stimulating, students become curious and facilitate immersion in the teachinglearning process (TLP) [5]. Simultaneously, students are able to use their mobile devices (BYOD) anywhere, anytime, in order to continuously learn and stay active. In this context, according to Toktarova $\mathrm{V}$., et al. [6] there are new requirements for the design and development of educational mobile applications, or the use of existing applications, to making your application on effective TLP: (i) integration with multiple systems and e-learning services; (ii) Adequate supply of content for effective learning; (iii) Distribution of learning materials in various shapes and sizes; (iv) ergonomics, simplicity and the possibility of working with educational web applications; (v) stability, reliability and productivity, provide efficient utilization and high availability of the application for a large number of students at the same time. These factors lead to an increased number and complexity of tasks.

$\mathrm{RE}$ is a stage in the software life cycle and the success of the final product - software system - critically depends on the designer's understanding the problem to be solved. This understanding is compiled into a formal document - Software Requirements Specification (SRS), which should unambiguously, completely and consistently describe requirements [7].

$\mathrm{RE}$ process is an ongoing and interplaying/iterative. Nevertheless, there are several approaches that diverge on the definition of which activities need to be satisfied in the RE process. [12] claimed that in context of a RE course the process is composed by five activities - Elicitation; Analysis, Negotiation and Prioritization, Modeling and Specification; Documentation and Validation. In this paper it is explored the Modeling and Specification (MS) requirements integrated into TLP (TLP-MS) activity with UML of the BML Context Oriented (BML-CO) model [8] with use of Lucidchart tool in a collaborative approach.

\footnotetext{
${ }^{1}$ http://www.molenet.org.uk/
} 
The rest of the paper is organized as follows. In the next section, a background of the addressed subjects is presented. The state of the art is described in the section III. In section IV it is presented the proposal, while in section $\mathrm{V}$ it is presented the practical application. Finally, in the last section, conclusions are discussed.

\section{BACKGROUND}

\section{A. $\quad$ m_learning}

m-learning can be defined as a form of learning that makes use of mobile technology and gives students the ability to learn anywhere and at any time. That definition is a result of the following m-learning definitions: (i) "Any sort of learning that happens when the learner is not at a fixed, predetermined location or learning that happens when the learner takes advantage of the learning opportunities offered by mobile technologies." [9]; (ii) "The use of wireless and mobile networks to facilitate, support, enrich learning and provide greater educational coverage" [10]; (iii) "E-learning through the use of mobile devices (smart-phones, tablets, handhelds, etc.), that provides mobility to students" [11]; (iv) "Educational activities through the use of compact and portable devices that allow students to master learning materials more effectively consume and create information" [12].

According to [13] the main benefits of m-learning are the perspectives of ubiquitous and pervasive learning. Continuous learning opportunities and lifelong, without restrictions of time and space. The implementation of m-learning offers students the opportunity to enjoy absolute flexibility, collaboration, freedom and just-in-time learning [14]. Another clear advantage of mobile learning is to support the communication and increase student-student and student-teacher interactions [15]. A real-time monitoring is carried out of students' progress. This monitoring will make it possible for students to adjust their performance with the teacher's help [16].

Cost issues related to m-learning are minimal, since the implementation of m-learning systems is encouraged in open source platforms, technologies and operating systems such as Android, iOS and others. Students can explore this opportunity to learn and develop free applications [17]. Technological innovations are not immune to the challenges, and the $\mathrm{m}$ learning also has its limitations with regard to technical, security, social and learning challenges [18].

\section{B. Modeling Systems}

The modeling systems aims to provide a specification that will guide developers in other stages of software development, namely design, implementation and testing of the system as referred in previous section. In this context there are several approaches for modeling and specify requirements as summarized in Table 1.

TABLE I. SPECIFICATION TECHNIQUES (FONTE:[19])

\begin{tabular}{|l|l|}
\hline Technique & Description \\
\hline $\mathrm{i}^{*}$ or KAOS & $\begin{array}{l}\text { Specifying agents, goals, and formal properties with formal } \\
\text { languages to enable reasoning about goals and goal- } \\
\text { achievement. }\end{array}$ \\
\hline $\begin{array}{l}\text { Natural } \\
\text { Language }\end{array}$ & $\begin{array}{l}\text { Specifying requirement with words and sentences to achieve } \\
\text { specification flexibility and understandability. Language } \\
\text { templates may be used to improve precision }\end{array}$ \\
\hline
\end{tabular}

\begin{tabular}{|l|l|}
\hline $\begin{array}{l}\text { SA } \\
\text { Diagrams }\end{array}$ & $\begin{array}{l}\text { Specifying functions, processes, structure, and behavior with } \\
\text { one of the graphical notations proposed by structured } \\
\text { analysis to achieve precision and make structure visible. }\end{array}$ \\
\hline Tables & $\begin{array}{l}\text { Specifying concepts to achieve an understanding of the } \\
\text { terminology and or rules for how conditions affect system } \\
\text { behavior }\end{array}$ \\
\hline UML & $\begin{array}{l}\text { Specifying functions, scenarios, processes, rules, relations, } \\
\text { behavior, and deployment with graphical notations from the } \\
\text { Unified Modelling Language to increase precision and show } \\
\text { structure. }\end{array}$ \\
\hline $\begin{array}{l}\text { User } \\
\text { Screens }\end{array}$ & $\begin{array}{l}\text { Specifying the user interface with paper or tool-based mock- } \\
\text { ups to increase the tangibility and authenticity of the planned } \\
\text { system. }\end{array}$ \\
\hline
\end{tabular}

In the present proposed approach to the teaching learning modeling and specifications it was adopted the Unified Modeling Language - UML [20] since it is methodologyindependent and it is accepted (adopted) by the academy (researcher and teachers) and industry that work in this field as a tool for modeling systems based on Object Oriented [21], $[22]$.

\section{RELATED WORK}

As referred in section $1 \mathrm{RE}$ is the process by which the requirements for software products are gathered, analyzed, documented, and managed throughout the SE lifecycle. RE is concerned with interpreting and understanding stakeholders' goals, needs and beliefs. As RE is one of the main contributors to the success of software projects.

Modeling and specification of requirements is an RE activity that represents a conceptual formalization of the system view which occurs when it originates a model [23]. This activity allows breaking the problem-solving process down into separate views (according to the diagram - use case, class diagram, etc.). Their teaching is not a simple task since it requires a great capacity of abstraction by the students [24], [25].

In the literature there some proposed approaches for teaching RE [8] and in particular modeling and specification requirements using UML. Sien [25] proposes that a teacher should (1) expose students to a variety of case studies describing different problem domains; (2) provide opportunities for students to work in teams to produce UML models; (3) adopt concept maps as a graphical representation of fundamental concepts and their relationships within a problem domain. Rivera-Lopez et al. [26] propose an approach that uses a subgroup of UML diagrams - class diagram and sequence diagram, or class diagram and state chart diagram. The approach aims that the students learn to analyze problems and to design solutions to these problems using the object oriented approach. Engels, et al. [27] propose an approach that use UML as a vehicle for teaching such core concepts of software engineering with the support of Multimedia elements and tools. In [28] the authors propose an approach using SysML/UML. In this approach essentially the authors emphasize the teamwork involving small modeling tasks targeted at specific type of diagram. Also they propose discussions and teacher feedback which are the keys to improve study results of systems modelling.

Yamazaki and Jiromaru [29] proposed instructional design to teach UML. The instructional design of teaching materials for the students literacy, and assess their effectiveness. Their strategy includes three levels of instruction, each with 
numerous step-by-step exercises. The students learn 10 basic patterns of UML notation at level 1, composition of the notation at level 2, and creating UML system diagrams at level 3. Kuzniarz and Staron [30] propose a set of best practices for teaching UML Based Software Development. The practices are basically of two basic types - pedagogy wise and subject wise. The first practice is the consistency between all artefacts in the entire process and, the second concerns realization of the students' projects. An active learning framework for instructors to describe modeling guidelines of the $\mathrm{OO}$ analysis and design method and for students to learn the method based on the instructors' guidelines is proposed by Kim e al.

From the presented approaches we can conclude that teaching modelling and specification requirements is a difficult task to teachers and students and there not exist an ideal/standardized approach that solve this problem.

\section{PROPOSAL: TLP-MS: SELECT TOOLS AND DEVICES}

In general thesis, we can state that it is important that teachers consider the learning styles of students when designing and developing modeling systems teaching materials. Although it may not be essential for teachers to test and instruct students in all situations, testing them with the VARK instrument - simple and fast - can provide important information that is beneficial to create an effective learning environment. Being aware of different learning styles and considering its impact on learning environments are the two first steps towards an essential understanding of the students' profiles when developing activities to teach modeling systems.

\section{A. Research methodology}

The obtained results are be based on a research technique that makes use of pre and post-tests that measure the knowledge acquired by students in a learning activity. Such tests consist on the application of a set of questions that must be answered by students before and after a particular activity. In particular, the pre-test allows assessing the participants' level of knowledge on an issue that will be approached before training. The post-test consists in applying a set of questions with the same level of difficulty, in order to assess the evolution of the acquired skills [31].

\section{B. Methodology}

In order to counter the problem addressed in section III we proposed a methodology [32] that should help HEI students acquiring modeling systems concepts. As discussed previously it is important to define the students profile in order to help designing and developing teaching materials. This assumption was the basis for the development of the methodology that is here proposed (Fig. 1). It consists of five different steps with a defined sequence: (A) Analysis of student profile; (B) Construction didactic material; (C) Select tools and devices; (D) Defining evaluation methodologies and (E) Monitoring and control.

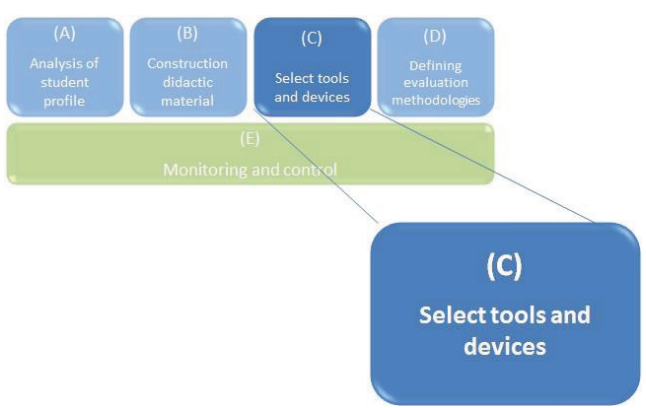

Figure 1. Methodology steps.

Teachers should consider the different learning styles of students while designing the teaching modeling systems and throughout the development modeling systems activities. Despite the fact that it may not be highly essential for teachers to test and instruct students in all situations, testing them with the VARK instrument - simple and fast - can provide important information to create an effective learning environment. It should be once again highlighted that being aware of learning styles and considering its impact on the learning environments are the two first steps towards an essential understanding of the profile of the students when developing modeling systems skills.

In the component (A) the VARK questionnaire is used to analyses the profile of each one of the students who attend modeling systems courses in order to understand what kind of teaching materials need to be built and made available for (B) (for instance, it is assessed if those materials should be more descriptive or visual, etc). Based on the results and constructed materials it is necessary to carry on their distribution to different types of devices, namely, if the model is applied to classroom teaching, distance learning (e-learning), blended learning (b-learning), or to be used only in mobile devices (mlearning) (C). For instance, the use of e-learning or m-learning demands the production of materials appropriate for such type of devices. Some of the most important components in the teaching-learning models are the used evaluation methodologies (D). The whole methodology has a monitoring and control process (E) which allows the adjustment of the materials, devices used and evaluation methodology, as long as students and teachers understand these needs.

\section{Select tools and devices}

One of the great issues when choosing a tool to teach modeling systems is the large amount and variety of tools, which makes it a great challenge. As there are several tools the following questions must be answered before the selection: Where to start? and How to choose the best modeling systems tools that could be adopted with mobile devices that meets the needs of HEI students?

Due to the large number and variety of modeling systems tools it is necessary to establish a set of characteristics: (i) Platform (Desktop, Web, Mobile); (ii) What are the operating systems that support (Windows, Mac, Linux, Other); (iii) Mobile device type (Tablet, Smartphone); (iv) Cost (Commercial, Free). In Table 1 there is presented one set of 24 tools which demonstrates the stated quantity and diversity of modeling systems tools 
TABLE II. SURVEYED TOOLS

\begin{tabular}{|c|c|c|c|c|c|c|c|c|c|c|}
\hline \multirow{3}{*}{ Nome } & \multicolumn{8}{|c|}{ Platform } & \multirow{2}{*}{\multicolumn{2}{|c|}{ Cost }} \\
\hline & \multicolumn{3}{|c|}{ Desktop } & \multirow{2}{*}{$D$} & \multicolumn{4}{|c|}{ Mobile } & & \\
\hline & $A$ & $B$ & $C$ & & $E$ & $F$ & $G$ & $H$ & $I$ & $\boldsymbol{J}$ \\
\hline AndyUML & & & & & $\mathrm{x}$ & & & & & \\
\hline astah* UML & $\mathrm{x}$ & & & & & & $\mathrm{x}$ & & & \\
\hline Cacoo & & & & $\mathrm{x}$ & & & & & & $\mathrm{x}$ \\
\hline Chrons Web Modeler & & & & $\mathrm{x}$ & & & & & & $\mathrm{x}$ \\
\hline ckwnc & & & $\mathrm{x}$ & $\mathrm{x}$ & & & & & & $\mathrm{x}$ \\
\hline Creately & $\mathrm{x}$ & $\mathrm{x}$ & $\mathrm{x}$ & $\mathrm{x}$ & & & & & & \\
\hline Cubetto & $\mathrm{x}$ & $\mathrm{x}$ & $\mathrm{x}$ & & & $\mathrm{x}$ & $\mathrm{x}$ & & $\mathrm{x}$ & \\
\hline Draw UML & & & & & & & $\mathrm{x}$ & & & \\
\hline draw.io & $\mathrm{x}$ & $\mathrm{x}$ & $\mathrm{x}$ & $\mathrm{x}$ & & $\mathrm{x}$ & $\mathrm{x}$ & & & \\
\hline DrawExpress Diagram & & & & & & $\mathrm{x}$ & & & & $\mathrm{x}$ \\
\hline GenMyModel & $\mathrm{x}$ & $\mathrm{x}$ & $\mathrm{x}$ & $\mathrm{x}$ & & & & & & $\mathrm{x}$ \\
\hline Grapholite & & $\mathrm{x}$ & & & $\mathrm{x}$ & & & $\mathrm{x}$ & $\mathrm{x}$ & \\
\hline Idatto & $\mathrm{x}$ & & & & & $\mathrm{x}$ & & & $\mathrm{x}$ & \\
\hline iUML & & & & & & $\mathrm{x}$ & & & & \\
\hline jsUML2 & & & & $\mathrm{x}$ & & & & & & $\mathrm{x}$ \\
\hline Lucidchart & $\mathrm{x}$ & $\mathrm{x}$ & $\mathrm{x}$ & $\mathrm{x}$ & $\mathrm{x}$ & & $\mathrm{x}$ & & & $\mathrm{x}$ \\
\hline MagicDraw Reader & & & & & & $\mathrm{x}$ & & & & \\
\hline PlantUML & $\mathrm{x}$ & $\mathrm{x}$ & $\mathrm{x}$ & $\mathrm{x}$ & $\mathrm{x}$ & & & & & $\mathrm{x}$ \\
\hline Syngraph.me & & & & $\mathrm{x}$ & & & & & & $\mathrm{x}$ \\
\hline UML Diagram Tool & & & & & & & & & & \\
\hline UML Process Aid & & & & & & $\mathrm{x}$ & & & & \\
\hline UML SketchClass & & & & & & & $\mathrm{x}$ & & & $\mathrm{x}$ \\
\hline VisiTouch & & & & & & $\mathrm{x}$ & $\mathrm{x}$ & & $\mathrm{x}$ & \\
\hline yUML & & & & $\mathrm{x}$ & & & & & & $\mathrm{x}$ \\
\hline
\end{tabular}

A - Mac; B - Windows; C - Linux; D - Web; E - Android; F - iPhone; G iPad; H - Windows Mobile; I - Commercial; J - Free

As a final remark, it was concluded that Lucidchart is the most appropriate tool for modeling systems courses that adopt m-learning.

\section{PRATICAL APLICATION}

\section{A. Course overview}

The RE course was designed following the ACM/AIS guidelines. It runs for 15 weeks (one semester) and consists of two hours of theoretical/practice lectures to discuss theory and 2 hours of practice (lab sessions), where students put in practice the learned theory they have learnt.

The main goal of the course is to induce students for the use of $\mathrm{RE}$ in their future work as designer in the development of software systems. Teaching RE is not only to provide students with solid concepts of the subject, but also to expose them to real problems.

As referred in section 1 we consider five activities in ER process - (1) Elicitation; (2) Analysis, Negotiation and Prioritization, (3) Modeling and Specification; (4) Documentation, and (5) Validation. These activities are not independent of each other; information obtained in one of them can serve for the other activities. At any time the designer may need to go back for example to clarify one a requirement or he/she can go on to the next activity. Our proposed approach is about topic (3) modeling and specification.

After having a catalog of requirements typically written in natural language, it is necessary to express these same requirements through models. Models are graphical representations of the requirements - which represent the problem to be solved - that giving different visions of the solution. It is important to emphasize that the modeling is conceptual, since it is intended to define "what" and not "how".
Modeling focus on application of "rules" in order to produce useful and verifiable, requirements, model. It is important to point out the difference between a model, which could be in UML, and a set of diagrams. A diagram is a partial graphic representation of a system model. The set of diagrams need not completely cover the model and deleting a diagram does not change the model. The model may also contain documentation that drives the model elements and diagrams (such as written use cases) [20].

In the proposed approach it is used UML language and it is intended to produce three diagrams types (1) Use Case, (2) Class and (3) Sequence. Those diagrams give different visions of the system: 1. Use Case diagram(s) give a functional vision - capture business requirements and illustrate the interactions between the system and its environment; 2. Class diagram give a structural vision - illustrate the relationships between classes modeled in the system; 3 . Sequence diagrams give a behavioral vision - illustrate the behavior of objects within a use case and in what order.

This proposed approach is based on the approach presented in [8]. Summarily, the theoretical/practice lectures use the expositive method. However, it is still expected to have an active participation of students through direct interpellation between teacher and students and vice versa. In laboratory lectures students must solve case studies that approximate them to the real-world situations. In parallel, students should develop a group project whose goal is to acquire knowledge "Known to do" in a collaborative environment. It is intended that each concept, technique or tool presented/discussed in lectures, is put into practice by resolution of Case Studies and a Project which are solved during lectures and afterwards. In turn, the lectures take place in the context of collaborative work, where the ability to group works will be developed.

\section{B. Proposed approach}

Mainly, it is proposed the following steps in the modeling task (1) presentation/discussion of the rules/steps to the construction of each diagram and the rules to use the Lucidchart tool, (2) review the catalog of requirements (3) based on in catalogue of requirements propose to the students that collaboratively to model the different diagrams, according to the following sequence: (i) Use Case (ii) Class; and finally the (iii) Sequence, and (3) Models verification/validation.

\section{Case study}

In order to operationalize the proposed approach it was asked previously to students to collaboratively create the catalogue of requirements for the case study below, either in fixed or mobile context, design the Use Case diagram(s), Class diagram and Sequence diagrams. The selected theme of the case study is believed to be easily understood by students who should easily understand its system and the business environment.

\section{System Golf Club - ClubeGolf}

"...members renting equipment. A member could be a Full Membership or one of your dependents. When a person makes its registration in the "GolfClub" as a Full Membership, is given the right to nominate up to three dependents, for which is responsible. To the "GolfClub" is critical to identify exactly who rented the equipment, if the Full Membership or one of your dependents. 
However, for control purposes, the "GolfClub" wants to get more information about the Full Membership than about his dependents. About a Full Membership it is intended to know his name, email address, home phone number, work address, work phone, mobile phone, tax identification number and birth date. Only persons of greater age could Full Membership. From a dependent, only the name, email, birth date and relationship are needed. Both Full Membership and dependents have a registration number, which is single per Full Membership ..."

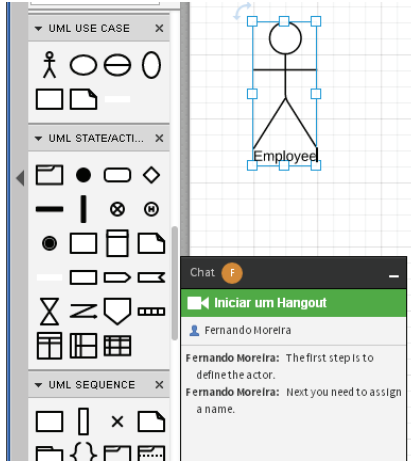

(a)

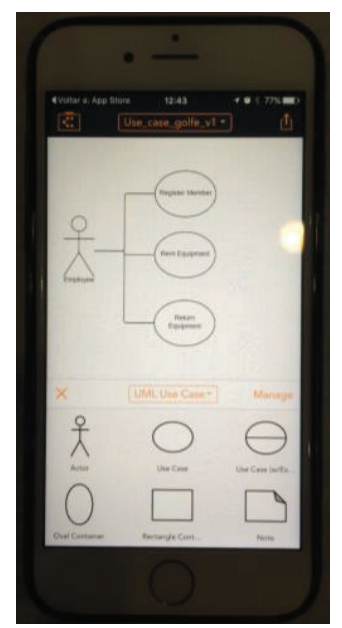

(b)
Figure 2. Use Case Diagram modelling by a group of student and followed by the teacher on laptop (a) and iPhone (b).

\section{Modeling requirements}

Step 1. Presentation of theoretical concepts.

Presentation/discussion of the rules/steps to the construction of each diagram and the rules to use the Lucidchart tool.

\section{Step 2. Review the catalog of requirements}

In this stage it is asked to students to review the catalog of requirements in order to remember the necessities (requirements) of the system for through the use of Google tools and tool Lucidcahart interact between the group members and the teacher to, collaboratively, modelling diagrams described above.

\section{Step 3. Modelling the different diagrams}

In this step, the students are allocated to working groups with different types of devices (laptops, smartphones and tablets). Guaranteed the basis for the work, the teacher through the Lucidchart chat regardless the students' location classroom or any other location or additionally students who are out of the classroom and have the need of a contact "faceto-face" uses a Hangout (integration with Google's tools) initiates the modeling of different diagrams (Fig.2).

To each group is created an independent document/page, shared by the group member and the teacher. In this way the teacher could supervise/monitor the tasks of each group, but each group do not see the work of the others groups.

As referred the modelling process is collaborative, since each element of the group has contributed in the modelling process. To follow up with feedback, the teacher monitors and suggests solutions/paths to the modelling of each of the diagrams in real time. This communication could be performed in two ways. The first one making itself the corrections in real time with the monitoring of the changes by the students (group), or the second one giving suggestions through messages in chat. These two ways could be used as independent or complementary ways.

In modeling the Sequence diagram (Fig. 3) the process is repeated, i.e. the teacher starts with an explanation task then makes the monitoring by providing feedback during the modeling process.

Students and teachers can also participate in the diagrams modelling through smartphones and tablets, in this case there is a native application for the Apple platforms (Fig. 2 (a) and Fig. 4). However, students who do not have Apple's mobile devices can perform the same tasks on their mobile devices using the browser application.

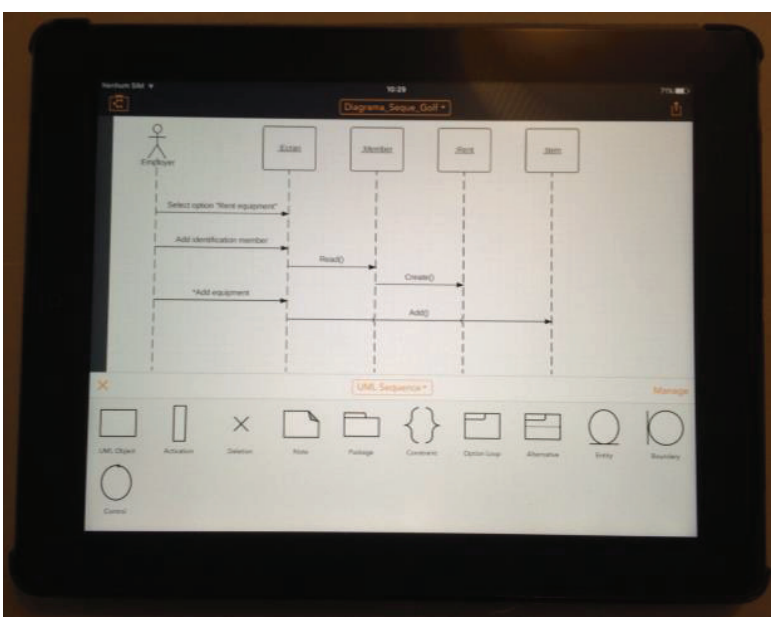

Figure 3. Modelling a sequence diagram usig an iPad.

\section{Step 3. Diagrams verification/validation}

Diagrams verification/validation task should occur at the end of the "construction" of each diagram. When students ends up modeling the Use Case diagram(s), it is verified/validated if they satisfy the requirements, then when students ends up modeling the Class diagram it is validate/verify if it satisfy the use cases diagram(s) and requirements, finally when students ends up modeling the Sequence diagrams they validate/verify with Use Case diagram(s) and Class diagram in order to eliminate/minimize inconsistencies and satisfy all the requirements. This step, as step 2 , could be monitored by the teacher and he/she could provide feedback during the all process.

\section{CONCLUSIONS}

$\mathrm{RE}$ is an important task in software life cycle. When the RE is not conduct correctly the consequences could be catastrophic namely late delivery systems and above the budgeted; the systems do not do what users expect; low quality and costs of maintenance and evolution are very high. In this way the acquisition of competences by students in a RE course of high education is fundamental in the job market. RE is an arduous task for teachers who transmit the knowledge and to students 
who have to understand and save this same knowledge. In order to contribute to improve the TLP it is proposed an approach TLP-MS for the modelling and specification activity using UML.

The proposed model is based on public domain free tools (easy and accessible to use anywhere and anytime), that helps students in their daily life inside and outside of the higher education institutions to solve problems collaboratively. That collaboration is promoting through the use of tools where students and teacher communicate/discuss and increment their work.

Currently, the approach is being operationalized with a class and at end of semester results will be analyzed and presented.

\section{REFERENCES}

[1] A. Y. Awadh and S. Higgins, "Effects of traditional, blended and elearning on students' achievement in higher education". Journal of Computer Assisted Learning, 29(3), 2013, pp. 220-234. http://dx.doi.org/10.1111/j.1365-2729.2012.00490.x

[2] Deepend, "Australian mobile device ownership and home usage report 2014". In Deepend, In-depth. Sydney, Australia: Deepend.

[3] T. Cochrane, and J. Oldfield, "iPadagogy 2.0: Exploring the affordances of the iPad for student-generated media production", 28th ascilite Conf., Hobart, Australia, 2011.

[4] F. Moreira, M. J. Ferreira, C. Pereira and N. Durão, "Collaborative Learning supported by mobile devices: A case study in Portuguese High Education Institutions". New Contributions in Information Systems and Technologies, ed. Álvaro Rocha; Ana Maria Correia; Sandor Costanzo and Luís Paulo Reis. Springer International Publishing, 2016, accept for publications.

[5] F. B. Osang, J. Ngole, and C. Tsuma, "Prospects and challenges of mlearning implementation in Nigeria: Case study National Open University Of Nigeria (Noun)," International Conference on ICT for Africa, February $20-23,2013$

[6] V. Toktarova, A. Blagova, A. Filatova and N. Kuzmin. "Design and Implementation of Mobile Learning Tools and Resources in the Modern Educational Environment of University", Review of European Studies; Vol. 7, No. 8; 318-324, 2015 http://dx.doi.org/10.5539/res.v7n8p318

[7] International Organization for Standardization (2011), ISO/IEC/IEEE 29148:2011 - Systems and software engineering - Life cycle processes - Requirements engineering,"

[8] F. Moreira and M. J. Ferreira, "Teaching and Learning Requirement Engineering based on Mobile Devices and Cloud: A Case Study". In Fonseca, D. and Redondo, E. (Eds.), Handbook of Research on Applied E-Learning in Engineering and Architecture Education, 2016, 237-262, IGI Global.

[9] C. Malley, G. Vavoula, J. Glew, J. Taylor, M. Sharples and P. Lefrere, "WP4-guidelines for learning/teaching/tutoring in a mobile environment", MOBIlearn/UoN, UoB, OU, 2003, Tech. Rep.

[10] The Mobile Learning Network (MoLeNET). "Mobile learning in practice". 2015, http://www. molenet.org.uk

[11] R. Gost, "Information and communication technologies in education (Elearning resources)". 2011, Moscow: Standard-inform.

[12] S. Wexler, J. Brown, D. Metcalf, D. Rogers and E. Wagner, "ELearning guild research 360 report: Mobile learning". Santa Rosa, CA: eLearning Guild. 2008

[13] Y. K. Baek and D. U. Cheong, "Present and future prospects for $\mathrm{m}-$ learning in Korea," Proc. of the 2005 IEEE International Workshop on Wireless and Mobile Technologies in Education (WMTE'05), pp. 28-30, DOI=10.1109/WMTE.2005.53.

[14] N. Y. Asabere, "Benefits and challenges of m-learning implementation: Story of Developing Nations," International Journal of Computer Applications, vol. 73 no. 1, pp. 0975-8887, 2013.

[15] T. H. Brown, "Towards a model for m-learning in Africa" International Journal on E-Learning, vol. 4, no. 3, pp. 299-315, 2005.
[16] S. Mahamad, M. N. Ibrahim, M. I. A. M Foad, and S. M. Taib "Open source implementation of m-learning for Primary school in Malaysia" International Journal of Social, Management, Economics and Business Engineering, vol. 2, no. 8, 2008, pp. 135-139.

[17] S. Mahamad, M. N. Ibrahim, M. I. A. M Foad, and S. M. Taib "Open source implementation of m-learning for Primary school in Malaysia" International Journal of Social, Management, Economics and Business Engineering, vol. 2, no. 8, 2008, pp. 135-139

[18] Straumsheim, C. "Digital Distractions". 2016. https://www.insidehighered.com/news/2016/01/26/study-use-devicesclass-nonclass-purposes-rise

[19] Fricker, S. A., Grau, R. and Zwingli, A. (2015) Requirements Engineering: Best Practice. Requirements Engineering: Best Practice. In Fricker, S. A., Thummler, C. and Gavras, A. (Eds.), Requirements Engineering for Digital Health, 25-46, USA: Springer. DOI: 10.1007/978-3-319-09798-5.

[20] OMG - Object Management Group (2016) Unified Modeling Language $(\mathbb{R})(\mathrm{UML}(\mathbb{R})$ Resource Page, Retrieved january 13, 2016, from http://www.uml.org/

[21] E. Ramollari and D. Dranidis, StudentUML: An Educational Tool Supporting Object-Oriented Analysis and Design, In proceedings of the 11 th Panhellenic Conf. on Informatics (PCI 2007), 2007.

[22] G. Engels, J. H. Hausmann, M. Lohmann and S. Sauer, Teaching UML Is Teaching Software Engineering is Teaching Abstraction, Lectures Notes in Computer Science, Vol. 3844, 2006, pp. 306-319.

[23] Machado, R.J., Ramos, I. and Fernandes, J. M. (1998). Specification of Requirements Models. Aurum, A. · Wohlin, C. (Eds.) Engineering and Managing Software Requirements, Berlin, Heidelberg: Sringer.

[24] Starrett, C. Teaching UML modeling before programming at the high school level. Proceedings - The 7Th IEEE International Conference On Advanced Learning Technologies, ICALT 2007, (Proceedings - The 7th IEEE International Conference on Advanced Learning Technologies, ICALT 2007), 713-714. doi:10.1109/ICALT.2007.234.

[25] Sien, V. An investigation of difficulties experienced by students developing unified modelling language (UML) class and sequence $\begin{array}{lll}\text { diagrams. Computer Science Education, 21(4), 317-342. } & \text {. }\end{array}$ doi:10.1080/08993408.2011.630127

[26] Rivera-Lopez, R., Rivera-Lopez, E and Rodriguez-Leon, A. Another approach for the teaching of the foundations of programming using UML and Java. In proceedigs of the CEA'09 Proceedings of the 3rd WSEAS international conference on Computer engineering and applications, 279-283.

[27] Engels, G., Hausmann, J., Lohmann, M., \& Sauer, S. Teaching UML is teaching software engineering is teaching abstraction. doi:10.1007/11663430_32.

[28] Kruus, H., Robal, T., \& Jervan, G. Teaching modeling in SysML/UML and problems encountered. Proceedings of The 25Th International Conference On European Association For Education In Electrical And Information Engineering, EAEEIE 2014, 33-36. doi:10.1109/EAEEIE.2014.6879380.

[29] Yamazaki, S., \& Jiromaru, T. Instructional design of exercise-centric teaching materials on UML modeling. Proceedings - 2014 IIAI 3Rd International Conference On Advanced Applied Informatics, 342-346. doi:10.1109/IIAI-AAI.2014.77.

[30] Kuzniarz, L., \& Staron, M. Best practices for teaching UML based software development. doi:10.1007/11663430_33.

[31] I-TECH, "Technical Implementation Guide. Guidelines for Pre- and Post-Testing". University of Washington. Seattle, Washington. USA, 2008.

[32] F. Moreira, and M. J. Ferreira, "Profile-oriented algorithms teaching: a proposed methodology". In Proceedings of the 10th Iberian Conference on Information Systems and Technologies (CISTI), Vol 2, pp 43-46, july 2015. 